\title{
Call for papers in special issue
}

Dr. Elton Moore, Director of the Mississippi State University Rehabilitation Research and Training Center on Blindness and Low Vision is doing a special issue for the Journal of Vocational Rehabilitation. Dr. Moore is interested in articles focusing on employment issues facing persons who are blind or severely visually impaired. Suggested topics include:

- SSI/SSDI Disincentives: What major disincentives are impacting on the employment of persons who are blind and what can be done to address these or promote work incentives?

- Randolph-Sheppard Issues: Are changes needed in the Randolph-Sheppard Vending Stand program to enhance self-employment opportunities for persons who are legally blind?

- African-American Issues: What special employment problems are faced by African Americans who are blind and what can be done to address these issues?

- Technology/Internet Accessibility Issues: What adaptive technology is currently available to deal with Graphic User Interface (GUI) issues and to what extent are people who are blind using this technology?

- Sheltered Employment: Are changes needed in the Javits Wagoner O'Day program that would expand employment opportunities for persons who are legally blind?

- Deaf-Blind Issues: What best practices and or strategies have been determined to be most effective in placing persons who are deaf-blind or who have multiple disabilities?

- Transition from School to Work: Are there unique strategies that are being used to en- hance the smooth transition from school to work for students who are blind?

- Public Attitudes: What strategies are most effective in changing attitudes of the general public toward persons who are blind and how do these attitudes impact upon employment opportunities for persons who are blind?

- Substance Abuse and Blindness: What job development/placement strategies are most effective in working with persons who are blind and are chronic substance abusers.

- Barriers to Employment: What are the most significant barriers to employment for persons who are blind and how can they be overcome?

- Congenital vs. Adventitious Blindness: Are there differences in employment outcomes for persons who are congenitally blind compared to those who are adventitiously blind and if so, what are the implications for vocational rehabilitation counselors?

Please contact Dr. Moore to indicate your interest. Papers must be submitted no later than March 1, 1998.

\author{
J. Elton Moore \\ Mississippi State University, \\ Rehabilitation Research and Training Center on \\ Blindness and Low Vision, \\ PO Drawer 6189, \\ Mississippi State, \\ MS 39762, USA \\ Voice: + 16013252001 \\ Fax: $\quad+16013258989$ \\ TDD + 16013258693
}

